\title{
Ảnh hưởng của các yếu tố sản xuất đến hiệu quả tài chính trong canh tác lúa của nông hộ Đồng bằng sông Cửu Long
}

\section{Affect of production factors on finance efficiency in rice cultivation of households Mekong Delta}

\author{
Cao Văn Hơn ${ }^{1}$, Nguyễn Lan Duyên ${ }^{1 *}$ \\ ${ }^{1}$ Trường Đại học An Giang, Đại học Quốc gia Thành phố Hồ Chí Minh, Việt Nam \\ *Tác giả liên hệ, Email: nlduyen@ agu.edu.vn
}

THÔNG TIN

DOI:10.46223/HCMCOUJS. econ.vi.16.3.994.2021

Ngày nhận: 29/09/2020

Ngày nhận lại: 14/12/2020

Duyệt đăng: 24/12/2020

Tù khóa:

canh tác lúa; hiệu quả tài chính; nông hộ

Keywords:

rice cultivation; finance efficiency; households

\section{TÓM TẮT}

Kết quả ước lượng bằng phương pháp bình phương bé nhất dựa trên dữ liệu sơ cấp được thu thập ngẫu nhiên qua khảo sát trực tiếp 338 nông hộ trồng lúa ở các tỉnh An Giang, Cần Thơ và Đồng Tháp thuộc đồng bằng sông Cửu Long nhằm thể hiện mối quan hệ cũng như mức độ tác động của các yếu tố sản xuất đến hiệu quả tài chính trong canh tác lúa của nông hộ trong vùng. Kết quả ước lượng cho thấy hai yếu tố có ảnh hưởng cùng chiều đến hiệu quả tài chính là số năm kinh nghiệm trồng lúa, lợi nhuận từ trồng lúa; và các yếu tố có ảnh hưởng ngược chiều đến hiệu quả tài chính với các mức ý nghĩa khác nhau đó là diện tích đất trồng lúa, tổng chi phí đầu tư cho các yếu tố đầu vào, thời gian sinh sống của chủ hộ, địa bàn cư trú ở Cần Thơ. Bên cạnh đó, nghiên cứu cũng xác định được các biến không có ảnh hưởng đến hiệu quả tài chính bao gồm NHANKHAU, TDHVCH, MANHDAT, TINDUNG, TAPHUAN, KCRUONG, LDONG và ANGIANG. Từ đó, bài viết đề xuất giải pháp khả thi góp phần nâng cao hiệu quả tài chính cho nông hộ trong vùng khảo sát thông qua tiết giảm chi phí sản xuất, nâng cao trình độ học vấn, ...

\section{ABSTRACT}

The least-squares estimations based on primary data of a random sample of 338 rice households in provinces of An Giang, Can Tho, and Dong Thap in the Mekong Delta show the relationship as well as the impact of the inputs on the finance efficiency of rice households. Results showed that two factors having a positive effect on finance efficiency are years of experience, rice cultivation profit; and the factors having a negative effect on the finance efficiency with various statistically significant including farm size, cost of capital, living time of the head of household, the residence in Can Tho. In addition, the study also identified variables that do not affect financial efficiency, including NHANKHAU, TDHVCH, MANHDAT, TINDUNG, TAPHUAN, KCRUONG, LDONG, and ANGIANG. Hence, the paper proposes solutions to improve the financial efficiency of the households due to reduce cost production, promote education level, and so on. 


\section{Giới thiệu}

Gạo là lương thực chủ yếu cung cấp cho hơn 03 tỷ người sinh sống trên toàn thế giới. Trong đó, hơn 1.1 tỷ người nghèo (có thu nhập ít hơn một đô la mỗi ngày) với phần lớn sống ở các nước thuộc châu Á, bao gồm cả Việt Nam (gần 700 triệu người) (Tan, Heerink, Kuyvenhoven, \& Qu, 2010). Đồng Bằng Sông Cửu Long (ĐBSCL) là vùng sản xuất lúa lớn nhất của Việt Nam, với diện tích năm 2018 là 4.1 triệu ha đã cung ứng 24.44 triệu tấn lúa cho nền kinh tế. Với sản lượng này ĐBSCL đã cung cấp 55.58\% tổng sản lượng lúa cả nước (Tổng Cục Thống Kê, 2018). Với những đặc điểm này cho thấy lúa là một ngành sản xuất quan trọng của vùng (Pham, Huynh, \& Tran, 2011). Đây là kết quả của việc ĐBSCL được liên tục bồi đắp bởi một lượng lớn phù sa từ sông Mê-kông khi đổ vào Việt Nam qua hai nhánh sông Tiền và sông Hậu. Ngoài ra, ĐBSCL còn được thiên nhiên ưu đãi về khí hậu với mưa thuận gió hòa, giúp nông hộ tưới tiêu và xả rửa mầm bệnh gây hại trên cây trồng. Từ đó cho thấy, ĐBSCL hội tụ đủ các điều kiện tự nhiên để tăng năng suất và sản lượng lúa. Song, thực tế cho thấy phần lớn nông hộ nơi đây chỉ tập trung vào khâu sản xuất (bố trí thời vụ, xuống giống, chăm sóc và phòng chống dịch bệnh) mà chưa chú trọng đến hiệu quả sử dụng vốn trong sản xuất lúa. Kết quả là nông hộ trồng lúa tiếp tục nghèo bởi hiệu quả sản xuất thấp và thu nhập bấp bênh. Do đó, nghiên cứu về hiệu quả tài chính trong sản xuất lúa là yêu cầu cấp thiết.

Để đo lường hiệu quả sản xuất nông nghiệp, nhiều nghiên cứu đã sử dụng các phương pháp đo lường khác nhau, cụ thể đo lường theo năng suất đất, năng suất lao động, hiệu quả đồng vốn, hiệu quả kỹ thuật, ... Mỗi phương pháp đo thể hiện một mục tiêu khác nhau của nhà nghiên cứu đối với nông hộ trồng lúa. Tuy nhiên, thực tế cho thấy có rất ít nghiên cứu sử dụng khía cạnh đo lường hiệu quả tài chính trong sản xuất lúa, mặc dù người trồng lúa luôn kỳ vọng có được lợi nhuận từ hoạt động sản xuất của mình. Vốn giúp nông hộ mua vật tư, giống, máy móc, thuê lao động, ... nhằm đảm bảo tính thời vụ và giảm thiểu rủi ro (Nguyen, 2014) và vốn có thể thu được từ nhiều nguồn khác nhau (Modigliani \& Miller, 1958) nhưng vẫn chưa được sự quan tâm sâu sắc từ phía các nhà nghiên cứu cũng như nông hộ.

Kết quả phân tích trên cho thấy, vốn là yếu tố rất quan trọng trong sản xuất lúa, đặc biệt là đối với nông hộ ở ĐBSCL. Tuy nhiên, theo hiểu biết hạn chế của tác giả, có rất ít nghiên cứu về vấn đề này. Vì vậy, bài viết "Ảnh hưởng của các yếu tố sản xuất đến hiệu quả tài chính trong canh tác lúa của nông hộ Đồng bằng sông Cưu Long” được thực hiện nhằm đề xuất các giải pháp giúp nông hộ sản xuất đạt hiệu quả cao hơn, đặc biệt hiệu quả tài chính.

\section{Phương pháp luận}

\subsection{Hiệu quả tài chính}

Theo Coelli, Rao, O'Donnell, và Battese (2005) năng suất là chỉ số đầu ra trên chỉ số đầu vào, theo đó hình thành năng suất vốn hay hiệu quả tài chính chính là sản lượng sản phẩm được sản xuất ra trên một đơn vị vốn. Theo Dinh (2003), hiệu quả tài chính là chỉ tiêu thể hiện hiệu quả của hoạt động sản xuất và là thước đo đánh giá hiệu quả về lợi nhuận của chi phí đầu tư trên đất.

Có nhiều cách khác nhau để đo lường hiệu quả hoạt động sản xuất và một trong những chỉ tiêu được sử dụng phổ biến trong hoạt động sản xuất nông nghiệp đó chính là tỷ suất lợi nhuận (Li, Feng, You, \& Fan, 2013; Mottaleb \& Mohanty, 2015; Schultz, 1964), hiệu quả chi phí (Nkonde, Jayne, Richardson, \& Place, 2015), và mức độ áp dụng máy móc thiết bị phục vụ sản xuất (Wickramaarachchi \& Weerahewa, 2018). Trên cơ sở đó, bài báo sử dụng phương pháp đo lường hiệu quả tài chính được khái quát hóa bằng phần trăm của lợi nhuận so với chi phí sản 
xuất (Li et al., 2013; Schultz, 1964) bởi đây là một chỉ tiêu hiệu quả tổng hợp của quá trình hoạt động của đơn vị, phản ánh trình độ tăng hiệu quả tài chính, nâng cao chất lượng hàng hóa, trình độ sử dụng vốn và tổ chức kinh doanh của đơn vị. Hiệu quả tài chính ngụ ý bình quân một đồng chi phí đầu tư cho các yếu đầu vào (không có hoặc có sự tham gia của lao động gia đình) sẽ thu được bao nhiêu đồng lợi nhuận. Hiệu quả tài chính càng cao thì hiệu quả sử dụng đồng vốn càng cao. Mức doanh lợi càng lớn thì hiệu quả hoạt động càng cao và khả năng tích lũy vốn càng lớn thể hiện qua công thức:

$$
\mathrm{HQTC}_{\mathrm{ij}}=\left(\mathrm{TR}_{\mathrm{ij}}-\mathrm{TC}_{\mathrm{ij}}\right) / \mathrm{TC}_{\mathrm{ij}}
$$

Trong đó, $\mathrm{HQTC}_{\mathrm{j}}$ là hiệu quả tài chính khi có và không có sự tham gia của lao động gia đình, TR là tổng giá trị sản lượng canh tác lúa của nông hộ, TC là tổng chi phí đầu tư cho các yếu tố đầu vào (bao gồm: giống, phân bón, thuốc bảo vệ thực vật, lao động, ... ), i chỉ nông hộ trồng lúa thứ $i$ và $\mathrm{j}$ thể hiện có hay không có sự tham gia của lao động gia đình.

\subsection{Các yếu tố ảnh hưởng đến hiệu quả tài chính trong canh tác lúa}

Các nghiên cứu đã sử dụng phương pháp ước lượng bình phương bé nhất để phân tích ảnh hưởng của diện tích đất canh tác lúa đến Hiệu Quả Tài Chính (HQTC) qua mô hình (2):

$$
\text { HQTC }_{\mathrm{ij}}=\beta_{1}+\beta_{2} \text { DIENTICH }_{\mathrm{ij}}+\varepsilon_{\mathrm{ij}}
$$

Nếu $\beta<0$ và có ý nghĩa thống kê thì tồn tại mối quan hệ ngược (Manjunatha, Anik, Speelman, \& Nuppenau, 2013; Xu \& Jeffrey, 1998) giữa diện tích đất với hiệu quả tài chính.

Tuy nhiên, công thức (2) thường bị chỉ trích do bỏ sót những yếu tố khác có ảnh hưởng đến hiệu quả tài chính như khác biệt trong chất lượng đất (Lamb, 2003). Lý thuyết kinh tế phát triển cho rằng hiệu quả tài chính bị ảnh hưởng bởi kiến thức và sự hiểu biết về kỹ thuật cũng như những vấn đế môi trường kinh tế xã hội trong đó nông dân phải ra quyết định (Kalirajan, 1990) và trên nền tảng những nghiên cứu trước đó đã lựa chọn hai trong số các chỉ tiêu môi trường kinh tế xã hội đó là giáo dục (Ureta \& Pinheiro, 1997; Mottaleb \& Mohanty, 2015), sự manh mún đất (Wu, Liu, \& Davis, 2005) và những yếu tố khác. Do đó, Li và cộng sự (2013) cùng với Nkonde và cộng sự (2015) đã cải tiến công thức (2) bằng việc bổ sung đầy đủ các biến vào mô hình:

$$
\text { HQTC }_{i j}=\beta_{1}+\beta_{2} \text { DIENTICH }_{i j}+Z \beta_{3}+X \beta_{4}+\varepsilon_{i j}
$$

Trong đó, $Z$ là vectơ các biến ngoại sinh chỉ đặc điểm của hộ, $X$ là vectơ các yếu tố về quản lý cây trồng có ảnh hưởng đến hiệu quả tài chính, $\beta_{\mathrm{i}}$ là các hệ số ước lượng và $\varepsilon$ là sai số ngẫu nhiên, $\mathrm{i}$ chỉ nông hộ trồng lúa thứ $\mathrm{i}$ và $\mathrm{j}$ thể hiện có hay không có sự tham gia của lao động gia đình. Từ đó, nghiên cứu hình thành mô hình thực nghiệm nhằm thể hiện mức độ tác động của các yếu tố đầu vào đến hiệu quả tài chính thông qua mô hình (4) với biến phụ thuộc là HQTC của hộ và các biến giải thích trong mô hình như sau:

$$
\begin{aligned}
& \text { HQTC }_{i j}=\beta_{1}+\beta_{2} \text { DIENTICH }_{i j}+\beta_{3} N H A N K H A U_{i j}+\beta_{4} \text { TĐHVCH }_{i j}+ \\
& \beta_{5} \text { TGDINHCU }_{i j}+\beta_{6} \text { THAMNIEN }_{i j}+\beta_{7} \text { TINDUNG }_{i j}+\beta_{8} \text { TAPHUAN }_{i j}+\beta_{9} \text { KCRUONG }_{i j}+ \\
& \beta_{10} \text { MANHDAT }_{i j}+\beta_{11} \text { CHIPHISX }_{i j}+\beta_{12} \text { LOINHUAN }_{i j}+\beta_{13} \text { ANGIANG }_{i j}+\beta_{14} \text { CANTHO }_{i j}+ \\
& \beta_{15} \text { LAODONG }_{i j}+\varepsilon_{i j}
\end{aligned}
$$

Ý nghĩa của các biến và kỳ vọng về dấu đối với các hệ số $\beta_{\mathrm{i}}$ trong mô hình (4) được trình bày trong Bảng 1 . 


\section{Bảng 1}

Kỳ vọng về dấu của các hệ số $\beta i$ trong mô hình (4)

\begin{tabular}{|c|c|c|c|}
\hline Tên biến & $\begin{array}{l}\text { Diễn giải và } \\
\text { đơn vị đo lường }\end{array}$ & Nghiên cứu có liên quan & $\begin{array}{l}\text { Kỳ vọng } \\
\text { về dấu } \beta_{i}\end{array}$ \\
\hline DIENTICH & $\begin{array}{l}\text { Diện tích đất canh tác lúa của nông } \\
\text { hộ (ha) }\end{array}$ & $\begin{array}{l}\text { M. Ali và Flinn (1989), F. Ali, } \\
\text { Parikh, và Shah (1994), Nkonde } \\
\text { và cộng sự (2015) }\end{array}$ & - \\
\hline NHANKHAU & $\begin{array}{l}\text { Tổng số thành viên trong gia đình } \\
\text { (người) }\end{array}$ & F. Ali và cộng sự (1994) & + \\
\hline TĐHVCH & $\begin{array}{l}\text { Trình độ học vấn của chủ hộ (số } \\
\text { năm học) }\end{array}$ & $\begin{array}{l}\text { M. Ali và Flinn (1989), F. Ali và } \\
\text { cộng sự (1994), Dhungana, } \\
\text { Nuthall, và Nartea (2004), Li và } \\
\text { cộng sự (2013), Mottaleb và } \\
\text { Mohanty (2015), Nkonde và cộng } \\
\text { sự (2015), Wickramaarachchi và } \\
\text { Weerahewa (2018) }\end{array}$ & + \\
\hline TGDINHCU & $\begin{array}{l}\text { Số năm sinh sống ở địa phương } \\
\text { (năm) }\end{array}$ & Nkonde và cộng sự (2015) & + \\
\hline THAMNIEN & $\begin{array}{l}\text { Số năm thâm niên trồng lúa của } \\
\text { chủ hộ }\end{array}$ & $\begin{array}{l}\text { Byiringiro và Readon (1996), Li } \\
\text { và cộng sự (2013) }\end{array}$ & + \\
\hline TINDUNG & $\begin{array}{l}\text { Số tiền vay được từ các tổ chức } \\
\text { chính thức và phi chính thức phục } \\
\text { vụ cho ruộng lúa (triệu đồng/năm) }\end{array}$ & $\begin{array}{l}\text { F. Ali và cộng sự (1994), Petrick } \\
\text { (2004) }\end{array}$ & + \\
\hline TAPHUAN & $\begin{array}{l}=1 \text { nếu chủ hộ có tham gia các lớp } \\
\text { tập huấn và }=0 \text { là ngược lại }\end{array}$ & $\begin{array}{c}\text { Li và cộng sự (2013), Gaurav và } \\
\text { Mishra (2015) }\end{array}$ & + \\
\hline KCRUONG & $\begin{array}{l}\text { Khoảng cách từ nhà ở của nông hộ } \\
\text { đến thửa ruộng lúa lớn nhất (km) }\end{array}$ & $\begin{array}{l}\text { Byiringiro và Readon (1996), D. } \\
\text { A. Ali và Deininger (2015) }\end{array}$ & - \\
\hline MANHDAT & $\begin{array}{l}\text { Số mảnh đất trồng lúa của nông hộ } \\
\text { (số mảnh ruộng) }\end{array}$ & $\begin{array}{c}\text { Bhalla và Roy (1988), Byiringiro } \\
\text { và Readon (1996), } \\
\text { Wickramaarachchi và } \\
\text { Weerahewa (2018) }\end{array}$ & - \\
\hline CHIPHISX & $\begin{array}{l}\text { Tổng chi phí đầu tư cho các yếu tố } \\
\text { đầu vào (triệu đồng/ha) }\end{array}$ & $\begin{array}{l}\text { Feder, Lau, Lin, và Luo (1990), } \\
\text { Manjunatha và cộng sự (2013) }\end{array}$ & - \\
\hline LOINHUAN & $\begin{array}{l}\text { Số tiền nông hộ nhận được sau khi } \\
\text { bán sản phâmm trừ đi chi phí cho } \\
\text { các yếu tố đầu vào (triệu đồng/ha) }\end{array}$ & Feder và cộng sự (1990) & + \\
\hline ANGIANG & $\begin{array}{l}=1 \text { nếu nông hộ sinh sống ở An } \\
\text { Giang và }=0 \text { nếu sinh sông ở } \\
\text { những tỉnh khác }\end{array}$ & Byiringiro và Readon (1996) & + \\
\hline CANTHO & $\begin{array}{l}=1 \text { nếu hộ sống ở Cần Thơ và }=0 \\
\text { nếu sống ở những tỉnh khác }\end{array}$ & Byiringiro và Readon (1996) & + \\
\hline LAODONG & $\begin{array}{l}\text { Tổng ngày công lao động làm việc } \\
\text { trên ruộng lúa (ngày/ha) }\end{array}$ & $\begin{array}{l}\text { Dhungana và cộng sự (2004), } \\
\text { Nkonde và cộng sự (2015) }\end{array}$ & - \\
\hline
\end{tabular}




\section{Phương pháp nghiên cứu}

Bài viết sử dụng bộ dữ liệu sơ cấp được thu thập thông qua phỏng vấn trực tiếp những người trực tiếp trồng lúa hoặc chủ hộ ở 03 tỉnh Cần Thơ, An Giang và Đồng Tháp thuộc ĐBSCL. Nguyên nhân bài viết chọn 03 tỉnh này là bởi nơi đây có những đặc trưng tương đồng về sinh thái, quy mô đất và khả năng sản xuất lúa (Dựa trên số liệu thống kê năm 2018 thì An Giang có diện tích đất lớn thứ hai sau tỉnh Kiên Giang và chiếm $15.58 \%$, Đồng Tháp chiếm $12.84 \%$ và Cần Thơ chiếm $5.59 \%$ so với tổng diện tích đất ở ĐBSCL (Tổng cục Thống kê, 2018). Những hộ được chọn một cách ngẫu nhiên trên cơ sở thông tin được cung cấp từ chính quyền địa phương. Điều này phản ánh chính xác thực tế sản xuất lúa của nông hộ và việc phỏng vấn được thực hiện trực tiếp bằng bảng câu hỏi soạn sẵn. Mỗi tỉnh tác giả chọn ra 03 huyện, mỗi huyện chọn ra 03 xã và mỗi xã chọn ra 03 ấp để tiến hành phỏng vấn nhằm đảm bảo tính đại diện và cỡ mẫu dự kiến đồng thời đảm bảo ý nghĩa khoa học. Cuộc khảo sát được tiến hành trong tháng 09 và 10 năm 2017 với những thông tin được thu thập gồm: đặc điểm nhân khẩu học của nông hộ, tình hình sử dụng đất, đặc điểm sản xuất lúa (các khoản chi phí và thu nhập) cho vụ Thu Đông 2016, vụ Đông Xuân và Hè Thu năm 2017 và cách thức quản lý trong quá trình canh tác lúa của mỗi nông hộ. Mẫu 338 nông hộ được phân phối ở các địa phương thuộc ĐBSCL dựa trên tỷ lệ phần trăm quy mô đất canh tác của các tỉnh trên địa bàn ĐBSCL như sau: 145 hộ ở An Giang (chiếm 42.90\% mẫu khảo sát), 74 hộ ở Cần Thơ (21.89\%) và 119 hộ ở Đồng Tháp (35.21\%).

Nghiên cứu sử dụng phương pháp phân tích lợi ích - chi phí (Benefit - Cost Analysis: $\mathrm{BCA}$ ) để mô tả bức tranh toàn diện về hiệu quả tài chính của nông hộ trồng lúa ĐBSCL. Trên cơ sở đó, nghiên cứu sử dụng phương pháp hồi quy đa biến để phân tích các yếu tố sản xuất ảnh hưởng đến hiệu quả tài chính của nông hộ trồng lúa ĐBSCL. Để đạt được kết quả, bài viết sử dụng phần mềm Stata 14.0 để thực hiện các kiểm định (chủ yếu là kiểm định sự vi phạm giả thiết về hiện tượng đa cộng tuyến và phương sai sai số thay đổi do bài viết sử dụng bộ dữ liệu không gian) cũng như khắc phục sự vi phạm giả thiết của mô hình (nếu có) với những biện pháp phù hợp nhất. Đồng thời, bài viết cũng trình bày các kết quả thống kê và kết quả ước lượng mô hình hồi quy tuyến tính sau khi khắc phục vấn đề.

\section{Kết quả nghiên cứu và thảo luận}

\subsection{Tổng quan về nông hộ trong mẫu khảo sát}

\section{Bảng 2}

Các chỉ tiêu cơ bản của nông hộ trồng lúa ĐBSCL năm 2017

\begin{tabular}{lccc}
\multicolumn{1}{c}{ Tiêu chí } & Đơn vị tính & Trung bình & Độ lệch chuẩn \\
\hline Số thành viên của hộ & Người/hộ & 4.41 & 1.40 \\
Số thành viên trên 16 tuổi & Người/hộ & 3.23 & 1.32 \\
Số thành viên trên 16 tuổi làm lúa & Người/hộ & 1.75 & 0.95 \\
Thu nhập khác ngoài làm lúa & Triệu & 19.68 & 21.27 \\
Tuổi chủ hộ & đồng/năm & 52.03 & 10.95 \\
Thời gian sinh sống của chủ hộ & Năm & 47.38 & 13.87 \\
Số tiền vay từ các tổ chức tín dụng & Triệu & 46.07 & 83.25 \\
Ngày công lao động gia đình làm lúa & đồngàm & 41.79 & 26.52 \\
Ngày công lao động thuê làm lúa & Ngày/ha & 35.70 & 22.80 \\
\hline
\end{tabular}

Nguồn: Kết quả được tổng hợp từ số liệu tự khảo sát (2017) 
Kết quả từ Bảng 2 cho thấy số thành viên trung bình của hộ là 04 người, trong đó số người trong độ tuổi lao động trung bình là 03 , đặc biệt số thành viên tham gia ruộng lúa là 02 người, đây là lực lượng lao động dự trữ sẵn sàng phục vụ cho hoạt động sản xuất lúa của gia đình. Số thành viên trung bình mỗi hộ ít có thuận lợi là dễ dàng ra quyết định khi có sự việc xảy ra, nhưng sẽ khó khăn trong sản xuất, đặc biệt là sản xuất lúa cần nhiều lao động (khi vào vụ). Thời gian sinh sống trung bình của chủ hộ là 47 năm và độ tuổi trung bình là 52 thể hiện đa phần chủ hộ sống bám trụ nơi mình sinh ra bởi họ dễ kiếm được thu nhập từ mảnh ruộng bờ ao của mình.

Thu nhập bình quân ngoài lúa của nông hộ khoảng 20 triệu đồng/năm cho thấy nông hộ ngày càng đa dạng hóa thu nhập của mình (công nhân - viên chức, buôn bán - làm dịch vụ và chăn nuôi gia súc - gia cầm). Đa dạng hóa thu nhập giúp nông hộ trang trải được các chi tiêu trong cuộc sống nhằm giảm gánh nặng đối với thu nhập từ lúa. Thời gian đầu tư cho sản xuất lúa của lao động gia đình bình quân khoảng 42 ngày/ha cùng với 38 ngày/ha đối với lao động thuê để chăm sóc ruộng lúa từ công đoạn làm đất cho đến thu hoạch.

Bên cạnh đó, hoạt động canh tác lúa đòi hỏi lượng vốn lớn để đầu tư cho các yếu tố đầu vào như giống, phân bón, thuốc bảo vệ thực vật, máy móc thiết bị, ... nhưng với số tiền tiết kiệm ít nông hộ không thể nào tái đầu tư sản xuất nên phải huy động thêm từ nhiều nguồn vốn khác nhau (như các tổ chức tín dụng chính thức, phi chính thức và bán chính thức) với số tiền trung bình là 46 triệu đồng/năm trong đó $53.55 \%$ từ các tổ chức tín dụng chính thức và $38.35 \%$ từ nguồn phi chính thức.

\subsection{Hiệu quả tài chính trong canh tác lúa của nông hộ ĐBSCL}

\section{Bảng 3}

Hiệu quả tài chính trong canh tác lúa của nông hộ ĐBSCL

Đơn vị tính: \%

Tiêu chí

Trung bình

Độ lệch chuẩn

\begin{tabular}{lcc}
\hline HQTC khi chưa tính Lao Động Gia Đình (LĐGĐ) & 179.28 & 102.68 \\
- Vụ Thu đông 2016 & 50.57 & 37.42 \\
- Vụ Đông xuân 2017 & 75.77 & 48.83 \\
- Vụ Hè thu 2017 & 53.94 & 37.83 \\
\hline Hiệu quả tài chính khi tính LĐGĐ & 127.76 & 85.41 \\
- Vụ Thu đông 2016 & 34.92 & 32.95 \\
- Vụ Đông xuân 2017 & 56.21 & 40.09 \\
- Vụ Hè thu 2017 & 36.63 & 32.30 \\
\hline
\end{tabular}

Nguồn: Kết quả được tổng hợp từ số liệu tự khảo sát (2017)

Bảng 3 cho thấy, hiệu quả tài chính trong canh tác lúa giữa ba vụ chênh lệch không đáng kể nhưng hiệu quả nhất vẫn là vụ Đông Xuân khi chưa tính lao động gia đình và có tính đến lao động gia đình tương ứng với mức trung bình là $75.77 \%$ và $56.21 \%$ và độ lệch chuẩn tương ứng là 37.42 và 40.09 . Sở dĩ vụ Đông Xuân đạt hiệu quả cao nhất so với các vụ khác trong năm chủ yếu do điều kiện thời tiết thuận lợi cho cây lúa phát triển và đây cũng là mùa vụ được nông hộ ưu tiên đầu tư canh tác để mang lại thu nhập cho gia đình. Nhìn chung, hiệu quả tài chính khi tính thêm lao động gia đình thấp hơn $52 \%$ so với khi chưa tính lao động gia đình bởi thời gian lao động gia đình tham gia chăm sóc và quản lý ruộng lúa nhiều hơn so với thời gian thuê mướn lao động địa phương. 


\subsection{Các yếu tố ảnh huởng đến hiệu quả tài chính trong sản xuất lúa của nông hộ}

\section{Bảng 4}

Các biến định lượng trong mô hình (4)

\begin{tabular}{lccccc}
\hline \multicolumn{1}{c}{ Tiêu chí } & Đơn vị tính & Trung bình & Lớn nhất & Nhỏ nhất & $\begin{array}{c}\text { Độ lệch } \\
\text { chuẩn }\end{array}$ \\
\hline DIENTICH & Ha & 1.81 & 19.5 & 0.10 & 2.02 \\
TĐHVCH & Số lớp & 6.10 & 15.00 & 0.00 & 3.51 \\
THAMNIEN & Năm & 29.69 & 60.00 & 6.00 & 10.95 \\
KCRUONG & Km & 4.55 & 73.00 & 0.01 & 9.58 \\
MANHDAT & Số mảnh & 1.08 & 3.00 & 1.00 & 0.32 \\
CHIPHISX & Triệu & 66.04 & 104.00 & 43.30 & 9.02 \\
- Chưa có LĐGD & đồng/ha & 73.59 & 106.26 & 56.00 & 9.06 \\
- Có tính LĐGD & & 77.49 & 194.48 & 25.94 & 28.30 \\
LAODONG & Ngày/ha & & & & \\
LOINHUAN & Triệu & 37.32 & 105.48 & 4.69 & 19.23 \\
- Chưa có LĐGD & đồng/ha & 29.77 & 99.84 & 1.79 & 18.73 \\
\hline
\end{tabular}

Nguồn: Kết quả tổng hợp số liệu tự khảo sát (2017)

Diện tích trồng lúa của nông hộ trong vùng nghiên cứu chỉ khoảng 02ha, trong đó có những hộ có diện tích rất nhỏ chỉ 0.1 ha. Điều này thể hiện sự manh mún đất đai và khó có thể vận dụng các máy móc thiết bị - công nghệ tiên tiến vào đồng ruộng. Số mảnh ruộng trung bình là 01 mảnh, đây chính là đặc điểm canh tác điển hình của nông hộ ĐBSCL do họ không có thói quen chia nhỏ quy mô canh tác thành nhiều mảnh ruộng khác nhau. Khoảng cách từ nhà nông hộ tới ruộng lúa trung bình $05 \mathrm{~km}$, có hộ cách xa ruộng đến $73 \mathrm{~km}$, điều này đã gây trở ngại lớn trong việc quản lý ruộng lúa của gia đình và ảnh hưởng đến hiệu quả sản xuất của hộ.

Biến CHIPHISX cho biết tổng số tiền mà nông hộ đầu tư cho các khâu trong quá trình canh tác lúa từ khâu đầu vào (chuẩn bị đất, giống, phân, thuốc ...) cho đến đầu ra (thu hoạch, phơi, vận chuyển ...) trung bình khoảng 66 triệu đồng/ha và 74 triệu đồng/ha khi chưa tính và tính sự tham gia của lao động gia đình. Tương tự, lợi nhuận thu được sau khi bán sản phẩm trừ cho tất cả các yếu tố đầu vào (kể cả lao động gia đình) khoảng 30 triệu đồng, tuy nhiên có những hộ chỉ đạt khoảng 02 triệu đồng/ha.

Bên cạnh đó, đa phần người dân trồng lúa có tham gia các lớp tập huấn (59.64\%) về kỹ thuật trồng lúa, thông tin về sử dụng các yếu tố đầu vào, thông tin thị trường sản phẩm đầu ra, ...

Trình độ học vấn của chủ hộ còn tương đối thấp trung bình khoảng 06 năm với độ lệch chuẩn là 04 năm, đây chính là trở ngại khá lớn cho nông hộ trong việc tiếp thu kiến thức và áp dụng khoa học kỹ thuật mới của các nước nông nghiệp tiên tiến vào hoạt động sản xuất của gia đình. Những hộ này có kinh nghiệm trồng lúa trung bình là 30 năm, đây là khoảng thời gian tương đối dài để họ tích luỹ kinh nghiệm trong quá trình trồng lúa góp phần gia tăng hiệu quả sản xuất cho nông hộ. Tổng ngày công lao động (gia đình và lao động thuê) làm lúa cao nhất là 195 ngày/ha và ngày công lao động tham gia canh tác lúa thấp nhất là 26 ngày/ha. 
Bài viết đã thực hiện các kiểm định về sự vi phạm các giả thiết của mô hình hồi quy tuyến tính khi ước lượng mô hình và kết quả cho thấy mô hình không vi phạm hiện tượng đa cộng tuyến do hệ số VIF trong mô hình khá thấp (HQTC là 1.26 và HQTCR là 1.28 ) nhưng vi phạm giả thiết về hiện tượng phương sai sai số thay đổi. Do đó, nhóm tác giả đã tiến hành khắc phục hiện tượng phương sai sai số thay đổi thông qua mô hình ước lượng robust với kết quả được trình bày chi tiết ở Bảng 5 .

\section{Bảng 5}

Các yếu tố ảnh hưởng đến hiệu quả tài chính trong canh tác lúa ĐBSCL

\begin{tabular}{|c|c|c|}
\hline Biến số & HQTC chưa tính LĐGĐ & HQTC đã tính LĐGĐ \\
\hline DIENTICH & $-0.0089 * *$ & $-0.0054^{*}$ \\
\hline NHANKHAU & 0.0041 & 0.0058 \\
\hline TDHVCH & -0.0019 & 0.0004 \\
\hline TGDINHCU & -0.0011 & $-0.0011 * *$ \\
\hline THAMNIEN & $0.0022 * *$ & $0.0021 * * *$ \\
\hline TINDUNG & -0.0000 & -0.0001 \\
\hline MANHDAT & 0.0335 & 0.0341 \\
\hline CHIPHISX & $-0.0236 * * *$ & $-0.0143 * * *$ \\
\hline TAPHUAN & -0.0094 & 0.0038 \\
\hline KCRUONG & 0.0006 & 0.0002 \\
\hline LAODONG & 0.0006 & -0.0001 \\
\hline LOINHUAN & $0.0491 * * *$ & $0.0436 * * *$ \\
\hline ANGIANG & -0.0058 & -0.0203 \\
\hline CANTHO & $-0.0364 *$ & $-0.0306^{* *}$ \\
\hline Hằng số & $1.4423 * * *$ & $0.9858 * * *$ \\
\hline Số quan sát & 338 & 338 \\
\hline $\mathrm{R}^{2}$ & 97.42 & 98.51 \\
\hline Prob $>\mathrm{F}$ & 0.0000 & 0.0000 \\
\hline
\end{tabular}

Ghi chú: $(*)$ có mức ý nghĩa $10 \%,(* *)$ có mức ý nghĩa $5 \%,(* * *)$ có mức ý nghĩa $1 \%$.

Nguồn: Kết quả được ước lượng từ số liệu tự khảo sát (2017

Kết quả ước lượng cho thấy, hai mô hình đều có ý nghĩa thống kê cao và đã chỉ ra được mối quan hệ nghịch giữa quy mô đất trồng lúa và hiệu quả tài chính trong cả hai trường hợp có và không có lao động gia đình. Bên cạnh đó, $\mathrm{R}^{2}$ trong các mô hình cao $(97.42 \%-98.51 \%)$ cho thấy các yếu tố này kiểm soát được từ $97 \%$ - 99\% sự biến động của hiệu quả tài chính, trong khi 
những yếu tố không quan sát được ảnh hưởng rất nhỏ đến hiệu quả tài chính.

Kết quả ước lượng cũng cho thấy các biến ảnh hưởng và có ý nghĩa thống kê đến hiệu quả tài chính trong hai trường hợp có và không có lao động gia đình gần như giống nhau. Điều này chứng tỏ hiệu quả tài chính của nông hộ có tính đến lao động gia đình hay không đều có ý nghĩa như nhau bởi hiệu quả đạt được chỉ giảm hơn trong trường hợp tính thêm chi phí cơ hội của lao động gia đình.

Biến DIENTICH có hệ số âm ở mức ý nghĩa 5\% trong trường hợp chưa tính đến lao động gia đình và $10 \%$ khi đã tính lao động gia đình. Kết quả nghiên cứu cho thấy mối quan hệ ngược chiều giữa diện tích đất canh tác và hiệu quả tài chính của những nông hộ trồng lúa, hàm ý diện tích đất càng nhỏ càng tốt và càng hiệu quả bởi họ tận dụng được nguồn lực nội tại của gia đình như lao động, đất đai, tư liệu sản xuất, ... (Fan \& Kang, 2005).

Biến THAMNIEN có hệ số dương ở mức ý nghĩa 5\% trong trường hợp chưa tính đến lao động gia đình và $1 \%$ khi đã tính lao động gia đình. Điều này ngụ ý, hiệu quả tài chính có mối quan hệ cùng chiều với số năm tham gia trồng lúa của nông hộ hay nói cách khác khi càng có nhiều kinh nghiệm trồng lúa thì chủ hộ càng hiểu rõ đặc thù trong canh tác, khả năng thích ứng linh hoạt trước những biến đổi của môi trường canh tác hay môi trường tiêu thụ sản phẩm đầu ra. Kết quả, hiệu quả tài chính sẽ gia tăng khi chủ hộ càng có nhiều kinh nghiệm trong canh tác lúa.

Tương tự, biến LOINHUAN có hệ số dương ở mức ý nghĩa cao $1 \%$ trong cả hai trường hợp chưa tính và có tính đến sự tham gia của lao động gia đình. Hàm ý, khi lợi nhuận thu được càng cao sẽ gia tăng số tiền tích lũy để tái đầu tư phục vụ sản xuất lúa đồng thời tránh được rủi ro thiếu vốn đầu tư cho các yếu tố đầu vào khi vào vụ.

Ngược lại, biến CHIPHISX có hệ số âm ở mức ý nghĩa cao $1 \%$ trong cả hai trường hợp, ngụ khi nông hộ càng cắt giảm chi phí sản xuất càng nhiều thì hiệu quả tài chính càng cao bởi chi phí sản xuất giảm sẽ gia tăng tính cạnh tranh của sản phẩm trên thị trường và góp phần cải thiện hiệu quả sản xuất.

Biến TGDINHCU cũng có mối quan hệ ngược với hiệu quả tài chính khi tính đến lao động gia đình với mức ý nghĩa $5 \%$, ngụ ý thời gian sinh sống của chủ hộ càng dài thì hiệu quả đạt được càng giảm do họ chủ quan trước những thay đổi của môi trường xung quanh. Đồng thời, biến CANTHO có hệ số âm ở mức ý nghĩa 10\% trong trường hợp chưa tính đến lao động gia đình và $5 \%$ khi đã tính lao động gia đình. Kết quả này cho thấy, những hộ sản xuất lúa sinh sống ở Cần Thơ thì khả năng quản lý ruộng lúa sẽ kém hiệu quả hơn so với những hộ sinh sống ở những địa bàn khác do đó làm giảm hiệu quả tài chính.

Những biến NHANKHAU, TDHVCH, MANHDAT, TINDUNG, TAPHUAN, KCRUONG, LDONG và ANGIANG không có ý nghĩa thống kê bởi thực tế cho thấy hiệu quả tài chính từ quá trình canh tác lúa của những nông hộ trong vùng khảo sát đều không bị ảnh hưởng bởi những ý tố này.

\section{Kết luận và khuyến nghị}

\subsection{Kết luận}

Qua kết quả ước lượng bằng phương pháp bình phương bé nhất dựa trên bộ dữ liệu thu thập được qua kết quả khảo sát trực tiếp 338 người dân trồng lúa trong địa bàn 03 tỉnh thuộc vùng sinh thái nước ngọt ở Đồng bằng sông Cửu Long. Kết quả cho thấy hiệu quả tài chính có sự chênh lệch khoảng 50\% khi có và không có sự tham gia của lao động gia đình, riêng vụ Đông Xuân luôn đạt được hiệu quả tài chính cao hơn so với 02 vụ còn lại trong năm. Bên cạnh đó, kết quả nghiên cứu cũng cho thấy có nhiều yếu tố có ảnh hưởng cùng chiều và ngược chiều với hiệu 
quả tài chính trong sản xuất lúa của nông hộ được khảo sát ở Đồng bằng sông Cửu Long. Trong đó, các yếu tố có ảnh hưởng ngược chiều đến hiệu quả tài chính với các mức ý nghĩa khác nhau đó là: diện tích đất canh tác lúa, chi phí đầu tư cho các yếu tố đầu vào, thời gian sinh sống của chủ hộ, địa bàn cư trú của nông hộ ở Cần Thơ; và hai yếu tố có ảnh hưởng cùng chiều đến hiệu quả tài chính là số năm tham gia trồng lúa, lợi nhuận từ trồng lúa. Mặt khác, bài viết cho thấy một số yếu tố không có ảnh hưởng đến hiệu quả tài chính của nông hộ với mức ý nghĩa 5\%.

\subsection{Khuyến nghị}

Từ kết quả nghiên cứu và thực tế ở 03 tỉnh Đồng Tháp, An Giang và Cần Thơ thuộc ĐBSCL, nghiên cứu có một số khuyến nghị nhằm giúp nông hộ sử dụng và đầu tư hợp lý các yếu tố đầu vào nhằm góp phần nâng cao hiệu quả tài chính như sau:

Nhà nước nên xây dựng lộ trình cụ thể (thời gian và địa bàn) về xả lũ (ngưng canh tác lúa vụ thu đông) để tăng độ phì nhiêu và cải tạo đất. Từ đó, góp phần giảm chi phí đầu tư cho đất và gia tăng hiệu quả tài chính.

Đa dạng hoá hệ thống trường lớp ở nông thôn và có chính sách hỗ trợ, khuyến khích người dân (nhất là những chủ hộ và những người trực tiếp sản xuất lúa) đến học để nâng cao trình độ giúp tiếp cận nhanh những công nghệ tiên tiến trên thế giới và vận dụng hiệu quả vào hoạt động sản xuất của hộ.

Nông hộ nên sử dụng các phương pháp mới để gia tăng hiệu quả tài chính đồng thời giảm bớt tác dụng không tốt lên sản phẩm lúa như khâu bón phân và thuốc bảo vệ thực vật do hàm lượng và liều lượng sử dụng hai thành phần này nhiều hơn so với khuyến cáo sử dụng. Điều này vừa gây tác dụng phụ cho lúa và đất đai vừa gia tăng gánh nặng cho nông hộ bởi chi phí đầu tư cho các yếu tố đầu vào của quá trình sản xuất khá cao.

Nông hộ nên quản lý và kiểm soát chặt chẽ lực lượng lao động tham gia sản xuất lúa của gia đình, đặc biệt là lao động gia đình bởi đây là lực lượng nòng cốt quyết định hiệu quả sản xuất do thái độ và tinh thần trách nhiệm cao trong công việc nên sẽ làm gia tăng hiệu quả sản xuất đồng thời giảm áp lực lao động khi vào vụ. Điều này sẽ giúp nông hộ vừa tiết kiệm chi phí sản xuất vừa tăng hiệu quả.

\section{Tài liệu tham khảo}

Ali, D. A., \& Deininger, K. (2015). Is there a farm size-productivity relationship in African agriculture? Evidence from Rwanda. Land Economics, 91(2), 317-343.

Ali, F., Parikh, A., \& Shah, M. (1994). Measurement of profit efficiency using behavioural and stochastic frontier approaches. Applied Economics, 26(2), 181-188.

Ali, M., \& Flinn, J. C. (1989). Profit efficiency among Basmati rice producers in Pakistan Punjab. American Journal of Agricultural Economics, 71(2), 303-310.

Bhalla, S. S., \& Roy, P. (1988). Mis-specification in farm productivity analysis: The role of land quality. Oxford Economic Papers, 40(1), 55-73.

Byiringiro, F., \& Reardon, T. (1996). Farm productivity in Rwanda: Effects of farm size, erosion, and soil conservation investments. Agricultural Economics, 15(2), 127-136.

Coelli, T. J., Rao, D. S. P., O'Donnell, C. J., \& Battese, G. E. (2005). An introduction to efficiency and productivity analysis (2nd ed.). New York, NY: Springer Publishing. 
Dhungana, B. R., Nuthall, P. L., \& Nartea, G. V. (2004). Measuring the economic inefficiency of Nepalese rice farms using data envelopment analysis. Australian Journal of Agricultural and Resource Economics, 48(2), 347-369.

Dinh, H. P. (2003). Kinh tế nông nghiẹp: Lý thuyết và thục tiễn [Agricultural economics: Theory and practice]. Ho Chi Minh City, Vietnam: Nhà xuất bản Thống Kê.

Fan, S., \& Kang, C. C. (2005). Is small beautiful? Farm size, productivity, and poverty in Asian agriculture. Agricultural Economics, 32(s1), 135-146.

Feder, G., Lau, L. J., Lin, J. Y., \& Luo, X. (1990). The relationship between credit and productivity in Chinese agriculture: A microeconomic model of disequilibrium. American Journal of Agricultural Economics, 72(5), 1151-1157.

Gaurav, S., \& Mishra, S. (2015). Farm size and returns to cultivation in India: Revisiting an old debate. Oxford Development Studies, 43(2), 165-193.

Kalirajan, K. P. (1990). On measuring economic efficiency. Journal of Applied Econometrics, 5(1), 75-85.

Lamb, R. L. (2003). Inverse productivity: Land quality, labor markets, and measurement error. Journal of Development Economics, 71(1), 71-95.

Li, G., Feng, Z., You, L., \& Fan, L. (2013). Re-examining the inverse relationship between farm size and efficiency: The empirical evidence in China. China Agricultural Economic Review, 5(4), 473-488.

Manjunatha, A. V., Anik, A. R., Speelman, S., \& Nuppenau, E. A. (2013). Impact of land fragmentation, farm size, land ownership and crop diversity on profit and efficiency of irrigated farms in India. Land Use Policy, 31, 397-405.

Modigliani, F., \& Miller, M. H. (1958). The cost of capital, corporation finance and the theory of investment. The American Economic Review, 48(3), 261-297.

Mottaleb, K. A., \& Mohanty, S. (2015). Farm size and profitability of rice farming under rising input costs. Journal of Land Use Science, 10(3), 243-255.

Nguyen, D. L. (2014). Các yếu tố ảnh hưởng đến thu nhập của nông hộ ở An Giang [Factors affecting farm household income in An Giang]. Tạp chi Khoa hoc Truòng Đại hoc An Giang, 3(2), 63-69.

Nkonde, C., Jayne, T. S., Richardson, R., \& Place, F. (2015). Testing the farm size-productivity relationship over a wide range of farm sizes: Should the relationship be a decisive factor in guiding agricultural development and land policies in Zambia. Paper presented at the World Bank Land and Poverty Conference, Washington D.C.

Petrick, M. (2004.) Farm investment, credit rationing, and governmentally promoted credit access in Poland a cross-sectional analysis. Food Policy, 29(3), 275-294.

Pham, T. L., Huynh, X. T. D., \& Tran, D. T. T. (2011). So sánh hiệu quả kinh tế của vụ lúa Hè Thu và Thu Đông ở Đồng bằng sông Cửu Long [Comparing the economic efficiency of summer-autumn and autumn-winter rice crops in the Mekong Delta]. Tạp chi Khoa hoc Truờng Đại học Cần Tho', 18(a) 267-276.

Schultz, T. W. (1964). Transforming traditional agriculture. New Haven, CT: Yale University Press. 
Tan, S., Heerink, N., Kuyvenhoven, A., \& Qu, F. (2010). Impact of land fragmentation on rice producers' technical efficiency in South-East China. NJAS-Wageningen Journal of Life Sciences, 57(2), 117-123.

Tổng cục Thống kê. (2018). Niên giám thống kê năm 2018 [Statistical Yearbook 2018]. Hanoi, Vietnam: Nhà xuất bản Thống kê.

Ureta, B. E. B., \& Pinheiro, A. E. (1997). Technical, economic, and allocative efficiency in peasant farming: Evidence from the Dominican Republic. The Developing Economies, $35(1), 48-67$.

Wickramaarachchi, N. C., \& Weerahewa, J. (2018). Relationship between land size and productivity: Empirical evidence from paddy farms in irrigation settlements of SRI LANKA. Sri LanKa Journal of Economic Research, 5(2), 125-142.

Wu, Z., Liu, M., \& Davis, J. (2005). Land consolidation and productivity in Chinese household crop production. China Economic Review, 16(1), 28-49.

Xu, X., \& Jeffrey, S. R. (1998). Efficiency and technical progress in traditional and modern agriculture: Evidence from rice production in China. Agricultural Economics, 18(2), 157-165. 